\title{
CARIDADE COMPULSÓRIA: FORMAS DE PRESSÃO POPULAR NA SOCIEDADE ROMANA TARDO-ANTIGA
}

\author{
Maria Luiza Corassin \\ Depto. de História
}

\begin{abstract}
RESUMO: Este artigo analisa duas cartas de Santo Agostinho sobre um tumulto em Hipona; nosso objetivo é estudar a violência urbana em uma cidade no período tardio de Roma, envolvendo as relações entre a aristocracia e a multidão.

ABSTRACT: This article analyses two letters of St. Augustine on a riot at Hippo; our purpose is to study the urban violence in a late Roman city, envolving the relations between the aristocracy and the mob.
\end{abstract}

PALAVRAS-CHAVE: Roma, Antiguidade Tardia, Sto. Agostinho, revolta urbana.

KEYWORDS: Rome, Late Antiquity, St. Augustine, urban rebellion.

As diferenças entre a cidade pagã e a comunidade cristã receberam análises baseadas em parâmetros variados. Paul Veyne ressaltou, no referente a evergetismo e caridade, que o evérgeta doa por diferentes razões: para marcar a sua distinção social, por patriotismo, por senso cívico; o seu gesto dirige-se a este mundo real. O doador cristão põe em prática a sua caridade para adquirir mérito diante de Deus; a sua generosidade se dirige a um outro mundo. O evérgeta dirige-se ao povo considerado como o conjunto dos cidadãos, o alvo do doador cristão são os "pobres", entendidos como uma categoria social e moral, não cívica. ${ }^{1}$ Andrea Giardina, em seu artigo Carità eversiva: le donazioni di Melania la Giovane e gli equilibri della società tardoromana, embora aceite esta distinção como válida em suas linhas fundamentais, pondera a necessidade de acrescentar a este esquema simétrico, de uma polaridade nítida, "uma

\footnotetext{
${ }^{1}$ Andrea Giardina comenta VEYNE, P. Le pain et le cirque. Sociologie historique d'un pluralisme politique. (Paris, Seuil, 1976, p. 44 seg.) e BROWN (1982, p. 131). Cf. GIARDINA, 1988, p. 127 , inclusive nota $\mathrm{n} .1$.
} 
certa cautela" em se tratando da época do Império romano tardio (GIARDINA, 1988, p. 127). Usando como documentação a biografia de Santa Melânia, ele procurou analisar as interações entre um certo tipo de doação cristã aristocrática e o equilíbrio da sociedade tardo-antiga. Desejando demonstrar que o comportamento extremado daqueles que desejavam se liberar de bens materiais representava um fenômeno que qualifica de "subversivo", tanto dentro da sociedade em geral quanto da comunidade cristã, Giardina termina por colocar em relevo a surpreendente reação dos escravos pertencentes a Melânia e a seu marido. Recusando a liberdade, os escravos preferiram permanecer no interior do oikos em que estavam radicados. Freqüentemente aos escravos eram entregues, tal como aos coloni, terras para serem cultivadas de forma autônoma, em exploração de caráter familiar; no entanto, achavam-se menos expostos (por motivos humanitários e econômicos) ao risco de venda e afastamento. Na Antiguidade tardia, a escravidão, em lugares e em circunstâncias específicas, podia se tornar uma condição privilegiada em comparação com a liberdade, para indivíduos desprotegidos, a quem podia faltar a proteção de um patronus poderoso (GIRADINA, 1988, p. 142).

A atenção despertada pelas figuras de Melânia e de seus familiares próximos nos conduziram a uma investigação em torno do comportamento de outro grupo social do mundo tardo-antigo: a comunidade cristã de Hipona.

Peter Brown, em uma conferência intitulada significativamente "Dalla plebs Romana alla plebs Dei" (BROWN, 1982), analisou a profunda mudança ocorrida na comunidade romana, entendendo por comunidade urbana romana a $U r b s$, formada pelo senado e populus Romanus. No decorrer dos séculos IV e V, esta comunidade que outrora se congregava nas celebrações rituais e nas distribuições evergéticas, presenciou a transferência dos loci de reunião para outros pontos, nos quais se expressava uma concepção di- versa da natureza da comunidade urbana, mediante formas muito diferentes de cerimônias e sobretudo mediante formas muito diversas de distribuição de doações. Brown considera as práticas caritativas associadas às devoções cristãs não apenas como um ato de piedade realizado privadamente, nem como uma forma de assistência econômica, mas sim como um catalizador simbólico importante por ser a nova definição da comunidade urbana cristã. Gradualmente desenvolveu-se uma nova relação, expressa pela distribuição de esmolas à plebs Dei, em locais muito diferentes dos anteriores existentes, ou seja, nas basílicas cristãs.

Dada a natureza explosiva da vida urbana tardoromana foram comuns as revoltas, linchamentos e incêndios, não apenas em Roma, mas também em outras cidades do Império. Desde há muito tempo haviam se desenvolvido estratégias de controle, partilhadas pelas classes superiores da cidade no seu conjunto. A relação entre a aristocracia residente e a plebs assumia uma feição intensamente pessoal; segundo Brown, as relações entre os membros pagãos e cristãos da aristocracia romana devem ser consideradas neste contexto. Vivendo em uma cidade em constante sobressalto, "os senadores de Roma por todo o século IV e $\mathrm{V}$ eram em primeiro lugar uma classe de governo e só secundariamente pagãos e cristãos". As famílias nobres, pagãs ou cristãs, sentiam-se compartilhando um mesmo ethos, em grande parte determinado por uma interpretação comum de seu papel na cidade. As diferenças de fé desapareciam em uma mesma linguagem de status social (BROWN, 1982, p. 127-28).

Para Brown, não se pode falar de uma continuidade direta entre a munificência tradicional e a esmola cristã. Tratava-se mais de uma "convergência" em grande parte inesperada, de dois sistemas paralelos no estrito sentido geométrico" (BROWN, 1982, p.131). A munificência tradicional envolvia somas imensas, acumuladas em um longo período e gastas em momentos solenes por um só doador de cada vez, como sinal de que se pertencia a um grupo privilegia- 
do dos senhores da cidade; no segundo caso, as esmolas cristãs consistiam num sistema de doações quase sem estrutura; somas pequenas ou médias eram oferecidas, a qualquer momento, por fiéis de todos os níveis sociais, sem distinção de sexo ou de fortuna, não como ostentação de riqueza, mas ao menos teoricamente, por uma necessidade espiritual. No primeiro caso, os beneficiários formavam uma categoria específica que podia incluir ricos ou humildes, mas que em sua maioria eram cidadãos válidos e ocupados. No caso cristão, os beneficiários das esmolas eram escolhidos por se constituírem os membros mais vulneráveis e inúteis da comunidade, os marginalizados, os doentes, os estrangeiros, símbolos da pobreza. O modelo "cívico" de sociedade, cuja unidade era a cidade antiga, definida em termos de "cidadãos" e "nãocidadãos", com uma hierarquia entre os cidadãos, em termos de relações entre a população, de uma parte, e seus magistrados, de outra, foi substituído por um modelo "econômico" mais amplo, no qual toda a sociedade, urbana ou rural, era considerada por intermédio da divisão entre ricos e pobres, expressandose a relação entre eles pelo gesto religioso da esmola (BROWN, 1982, p. 131-32).

O senso comum desenvolveu algumas obviedades costumeiramente repetidas: "em todas as sociedades tradicionais conhecidas, a doação teve uma função central na manutenção da posição"; "as doações são símbolos de prestígio, implicando uma subordinação de quem recebe, o qual se submete a uma obrigação: por isto a doação serve como meio de controle social". Edward P. Thompson em Società patrizia, cultura plebea (THOMPSON, 1982), vai mais além destas constatações comumente não contestadas. Ele considera possível individuar, sob o ângulo de quem ocupa a posição inferior, "de baixo", características diversas e mais determinantes que estas. "Doações de maior importância - a caridade e o subsídio de alimentos em tempos de penúria - são impostos de modo direto sobre os ricos pelos pobres por meio de uma prática bem conhecida de revoltas ou ameaças de revolta, uma prática que apresenta por si características estruturais (THOMPSON, 1982, p. 321-23). A "liberalidade" e a "caridade" podem ser consideradas como atos calculados de complacência de classe em períodos de miséria e como calculadas extorsões (sob a ameaça de tumulto) por parte da multidão. Aquilo que é visto, sob a ótica das classes superiores, como um "ato de dar", é visto de baixo como um "ato de obter" (THOMPSON, 1982, p. 361-62). As oportunidades eram aproveitadas quando se apresentava a ocasião, sem considerar muito as eventuais conseqüências; a multidão impunha seu poder em momentos de revolta, constrangendo membros da nobreza a fazer concessões.

Uma compreensão mais profunda da sociedade exige considerar o contexto em que atua a nobreza, de um lado, e a "multidão", de outro. A partir das proposições de Thompson, poderíamos investigar as relações entre a plebe e a classe dirigente, procurando individuar características e objetivos de revoltas envolvendo a participação de multidão no mundo romano?

É notória a apreensão existente no mundo urbano, dentro da sociedade romana, em relação ao perigo representado pela multidão incontrolada. Durante o Império, o comportamento da aristocracia residente em Roma continuou seguindo o padrão estabelecido há longo tempo para a munificência. Desenvolveram-se relações complexas entre os magistrados e a plebe urbana, que acabaram por se tornar tradicionais. A aristocracia incorporou ao seu comportamento a idéia de responsabilidade em proporcionar espetáculos à plebe ou de prestar auxílio em determinadas ocasiões. Por sua vez, a plebe também soube desenvolver formas de extorquir o que desejava: são bem conhecidas as manifestações públicas, sobretudo em locais de espetáculos, como forma de pressionar as autoridades.

No episódio que será examinado, ocorrido em 411, verifica-se a transferência para o ambiente cristão destas formas tradicionais de manifestação popu- 
lar. Neste caso, em lugar de existir uma nítida separação entre os dois sistemas representados pela caridade cristã e o evergetismo pagão, encontramos uma plebe tumultuante exigindo que um aristocrata rico assuma o papel de patrono da comunidade cristã. O local mudou: não ocorre no fórum, teatro ou circo, locais tradicionais de reunião cívica, mas na igreja. A autoridade presente não é mais o magistrado do Estado, mas um bispo cristão. No entanto, as relações face a face da cidade antiga persistem: o bispo Agostinho atua como negociador cauteloso, cuidando para encontrar o limite entre a concessão e a recusa firme, para evitar uma explosão exasperada do povo.

Dependendo do autor, a história de personagens como Melânia e Piniano pode mostrar apenas o doador em termos de sua motivação explícita, da construção de uma imagem de santidade e sua justificação ideológica. Um relato de tipo hagiográfico seria centralizado no comportamento caritativo cristão, associado ao modelo de vida espiritual de Santa Melânia.

O episódio adquire maior significação se analisado sob o ângulo das relações plebe/aristocracia, utilizando as considerações de Giardina, Brown e Thompson para orientar a interpretação daquilo que tem sido visto apenas como um incidente secundário na vida de santidade do casal.

Por intermédio de sua biografia ${ }^{2}$, sabemos que Melânia, considerada a maior herdeira do mundo romano em sua época, desejava dedicar-se inteiramente a Deus, consagrando-se à virgindade. Mas, dona de um patrimônio que se pretendia transmitir intacto, seus pais a casaram com a idade de quatorze anos com um primo, Valério Piniano, de dezessete

${ }^{2}$ Utilizamos a Vie de Sainte Mélanie, com texto grego e tradução de D. Gorce (Sources Chrétiennes, 90). No texto será citada como VITA MELANIAE. A introdução de Gorce contém os dados referentes à familia de Melânia, a Jovem e de Piniano. Sobre o casamento e a decisão de abandonar as suas riquezas, ver especialmente p. $36 \mathrm{seg}$. anos, filho de um ex-Prefeito de Roma. O relato do biógrafo de Melânia nos informa sobre os fatos que se seguiram. Após alguns anos de matrimônio, decididos a se devotarem à uma vida de castidade, Piniano e a esposa passaram a viver como "irmão" e "irmã". Determinados a "renunciar ao mundo", os jovens foram obrigados a enfrentar uma tempestade de protestos provocada pela resolução de se liberarem da riqueza e dos bens dos seus antepassados. Os novos ascetas instalam-se inicialmente no subúrbio de Roma, em sua villa da Via Ápia, adotando um comportamento considerado um desafio e uma ameaça à sua própria classe, pela forma radical de dilapidar seus bens. A oposição brotou de todos os lados: da família e até mesmo dos próprios escravos alarmados pela possibilidade de dissolução do patrimônio. Este comportamento tem justificadamente chamado a atenção de historiadores e merecido análise.

A liquidação total levou vários anos, dada a entidade do montante dos bens, o que tornava algumas propriedades invendáveis pela dificuldade de encontrar compradores suficientemente ricos e pela disseminação das mesmas, desde a Britânia até a África. Melânia, dedicada a uma vida de caridade sob todas as formas, buscando uma vida cristã perfeita de oração e mortificação, foi se liberando de suas riquezas, começando pelas propriedades mais expostas aos bárbaros, à medida que estes ameaçavam mais e mais Roma. Em 410, quando a cidade foi finalmente tomada por Alarico, Melânia deixou a Europa com o marido Piniano e a mãe, Albina, desembarcando na África. Os viajantes fixaram-se em Tagaste, junto ao bispo Alípio, amigo de Agostinho. Segundo a biografia (VITA MEL, 20), chegando à África o casal vendeu logo os bens que possuíam na Numídia, na Mauritânia e na própria província da África, utilizando o dinheiro para auxiliar os pobres e resgatar prisioneiros: "Gastando assim, sem contenção, eles se alegravam no Senhor". Decididos a vender todos seus bens, foram, no entanto, aconselhados pelos própri- 
os bispos da África, Agostinho, Alípio e Aurélio de Cartago a dar uma sede e um rendimento aos monastérios, em lugar de vender o patrimônio e doar dinheiro que seria dissipado em pouco tempo.

Tagaste, a cidade do bispo Alípio, era pequena e muito pobre. O casal a escolheu para se instalar, principalmente pela presença do bispo, do qual Melânia tornou-se amiga. É bem conhecida a importância assumida pelas mulheres da aristocracia romana que se tornaram o principal apoio da Igreja pelas suas relações com os bispos e suas doações. Melânia e sua mãe Albina passaram a ser personagens de destaque na comunidade. "Ela dotou a igreja deste santo homem com rendimentos e doações, jóias de ouro e prata, assim como tecidos preciosos, enquanto esta igreja era anteriormente muito pobre, de tal forma que o santo (Alípio) se tornou objeto de inveja para o restante dos bispos desta província" (VITA MEL, 21). A biografia se detém aqui; talvez o biógrafo julgou desnecessário registrar um episódio que dizia respeito basicamente ao marido. Para entender esta vaga alusão e para conhecer o estranho incidente que envolveu Piniano em Hipona precisamos recorrer a outro documento, a saber, a correspondência de Agostinho.

No momento em que Melânia e Piniano assistiam à missa em Hipona, o povo ali presente exigiu aos gritos que Piniano fosse ordenado presbítero, o que o ligaria (e a sua fortuna) a esta cidade. Este não era um procedimento totalmente inusitado; havia outros precedentes. Na Igreja cristã primitiva ocasionalmente a massa leiga podia exercer influência decisiva na eleição de um bispo de sua escolha. Cipriano, bispo de Cartago no século III, várias vezes usou a expressão suffragium plebis ou populi ou omnium em relação à eleição de bispos. É verdade que tanto na esfera secular quanto na eclesiástica as decisões oriundas das bases (tanto quanto existiam) tendiam a ser substituídas por decisões emanadas de cima; gradualmente a massa de leigos iria sendo excluída da participação efetiva na escolha de seus líderes na Igreja. A longo prazo o laicato perderia a voz que parece ter possuído nos tempos iniciais. Mas, em algumas áreas e em certa medida, os membros leigos da Igreja eram por vezes capazes de impor sua vontade. Na segunda metade do século IV homens excepcionais como Ambrósio, em Milão, e o próprio Agostinho, nesta mesma igreja de Hipona, foram eleitos bispos por uma irresistível pressão popular. Teoricamente a participação da comunidade leiga era um elemento essencial na eleição episcopal. Mas não existia um mecanismo adequado para a manifestação popular, a qual só podia se expressar na forma de aclamações tumultuosas (STE. CROIX, 1954, p.35-36).

Pressionado pela multidão, Piniano foi obrigado a jurar que se estabeleceria em Hipona e caso resolvesse se ordenar padre, ele só o faria nesta igreja. É possível reconstituir as linhas gerais do acontecido por intermédio de duas cartas de Agostinho, datadas de 411 d.C., dirigidas uma a Alípio (EPIST. CXXV) e outra a Albina (EPIST. CXXVI). Nestas duas cartas Agostinho procura se justificar perante o amigo Alípio e diante de Albina. Nelas o bispo assume a defesa do seu povo de Hipona: "o comportamento da multidão foi ditado não pela cobiça pelo dinheiro de Piniano, mas pelo desejo de reter junto a si este santo homem."

Na resposta enviada a Alípio (EPIST. CXXV) ele discute longamente uma questão que este lhe colocara em uma carta não conservada. Nesta epístola encontramos não a descrição do acontecido, desnecessária, pois Alípio estivera presente, mas uma espécie de discussão teórica centrada na proposição: "Eu ou o povo de Hipona consideramos que alguém está obrigado a cumprir um juramento extorquido pela violência?" 3 A resposta de Agostinho é positiva - é obrigação de Piniano cumprir sua promessa; conclui

\footnotetext{
${ }^{3}$ Em EPIST. CXXVI, 11, Agostinho reproduz a questão que Alípio the colocara; Scripsit mihi Sanctitas tua: Si aut ego aut Hipponenses hoc censent, ut jurejurando violenter extorto satisfiat.
} 
que "é errado ser infiel ao juramento", apesar das condições em que ele foi feito.

Nessa carta CXXV afirma ainda que, apesar de não estar sendo diretamente acusado, Albina o considera culpado de tentar reter "um servo de Deus entre nós por amor ao dinheiro" ${ }^{4}$; repele as suspeitas que recaem sobre o populus Hipponensis ter agido movido pela cupiditas. Sente-se mais atingido pelo fato de Albina nutrir suspeitas semelhantes sobre ele: De te quippe imperitum vulgus hoc sensit; de nobis, lumina Ecclesiae (EPIST. CXXV, 2). Fica evidente a distinção que Agostinho estabelece entre a "multidão ignorante" que formou uma má opinião sobre Alípio e a "luz da Igreja", Albina, que julga o mesmo sobre ele. Note-se que o dicionário registra para lumen tanto o sentido de "luz" como o de "apoio, arrimo, auxílio".

Defende-se usando argumentos pouco convincentes: seria tolice acreditar que o povo cobiçasse a riqueza do marido de Melânia; esta acusação apenas refletiria o ódio contra o clero, especialmente contra os bispos que eram suspeitos de usar e aproveitar os bens da Igreja como se fossem os proprietários ${ }^{5}$.

Sabemos que desde o século IV em diante a riqueza da Igreja crescera e logo os bispos das sedes mais importantes tornaram-se os administradores de grandes propriedades, dispondo de somas imensas. No início do século $\mathrm{V}$ os rendimentos de um bispo como o de Ravena eram maiores que os de um governador provincial (STE. CROIX, 1954, p. 46). Para o século IV temos o testemunho de Amiano Marcelino, ao relatar a acirrada disputa em torno da sede episcopal de Roma: "Considerando o esplendor da

\footnotetext{
${ }^{4}$ Quando enim nos credimur cupiditate pecuniae, non dilectione justitiae servos Dei velle retinere...(Epist. CXXV, 1).

${ }^{5}$ Verum omnis haec invidia non nisi in clericos aestuat, maximeque in episcopos, quorum videtur praeminere dominatus, qui uti fruique rebus Ecclesiae tanquam possessores et domini existimantur. (Epist. CXXV, 2)
}

cidade, não me admiro que aqueles que procuram obtê-la lutem com todas as forças para conseguir o que desejam; aquele que obtém tal cargo, está seguro de enriquecer com os oferecimentos das matronas, de andar de carruagem pelas ruas respeitavelmente vestido, superando no fasto dos banquetes a suntuosidade da mesa imperial" (AMM. MARC., XXVII, III, 14). Énecessário reconhecer que em seguida Amiano diz que o bispo de Roma deveria "imitar a vida exemplar de alguns bispos de província" pela sobriedade e temperança que estes demonstravam. Note-se que já na obra do pagão Amiano são perceptíveis os elementos que reaparecem na carta de Agostinho em 411: a importância das oblationes matronarum e a riqueza da Igreja e de seus bispos.

Na carta dirigida a Albina, Agostinho rememora a ocorrência: em tumulto, o povo pedia a ordenação de Piniano; havendo prometido a este não ordená-lo contra a sua vontade, ameaçou deixar de ser bispo da cidade, caso fosse forçado a romper esta promessa. Também não permitiria que fosse ordenado em sua Igreja por algum outro. Afirmou ainda que, caso Piniano fosse ordenado contra a própria vontade, este partiria de Hipona imediatamente após receber a ordenação. Como o clamor da multidão persistisse, Agostinho pensou em se retirar, mas temia que ela se tornasse mais exasperada e cometesse alguma violência contra o bispo Alípio de Tagaste também ali presente.

Piniano propôs então consentir em fixar residência em Hipona caso ninguém o obrigasse a aceitar a condição clerical. Agostinho consultou Alípio sobre isto, o qual se recusou a opinar. Dirigiu-se então novamente à multidão barulhenta para negociar. "Após conversar a meia-voz entre eles, pediram que a esta promessa e ao juramento, fosse acrescentada outra cláusula, a de que se ele alguma vez consentisse em aceitar ser clérigo, só o faria na igreja de Hipona".

$\mathrm{O}$ aspecto a destacar nestas cartas é a presença da "multidão" no relato de Agostinho. Nesta época de extrema turbulência na vida urbana, há outros regis- 
tros de revoltas nas quais magistrados chegam a perder a vida. Amiano Marcelino relata vários casos ocorridos em Roma no século IV, envolvendo prefeitos urbanos. Símaco, exponente da aristocracia, teve incendiada sua belíssima casa no Trastevere; a ira dos cidadãos foi despertada quando um plebeu inventou que o teria ouvido dizer que preferia apagar a cal no seu próprio vinho, do que vendê-lo pelo preço previsto. (AMM. MARC. XXVII, III, 4) Lampádio, que se tornou prefeito de Roma em 365, enfrentou vários tumultos durante sua administração. O mais grave ocorreu quando a plebs infima, reunida em grande número, teria ateado fogo com tochas e projéteis incendiários em sua casa, perto das termas de Constantino, se os vizinhos e os domésticos que acorreram em auxílio não a tivessem dispersado jogando pedras e telhas. Aterrorizado pela primeira vez com a agitação crescente (crebrescentes seditionis), ele se retirou para esperar que o tumulto se aplacasse. Amiano informa o motivo: o prefeito quando queria construir novos edifícios ou restaurar os antigos, se necessitasse de ferro, chumbo, bronze e outros materiais, mandava os funcionários buscarem o material, levando sem pagar; isto acabou despertando a ira dos pobres, que reclamavam dos freqüentes prejuízos sofridos (AMM. MARC. XXVII, III, 8-10). A outra agitação urbana registrada por Amiano ocorreu durante a luta entre os partidários de Dâmaso e Ursino que disputavam a sede episcopal de Roma, durando até 368. Segundo este autor, o tumulto resultou até em ferimentos e morte de adeptos de ambos. O prefeito da Urbe, Vivêncio, incapaz de controlar a situação, foi obrigado a se retirar para uma propriedade suburbana. Sabe-se que na basílica de Sicinino, atual S. Maria Maggiore, onde os cristãos se reuniam, foram encontrados cento e trinta e sete cadáveres (AMM. MARC. XXVII, III,14).

A própria biografia de Melânia informa que, pouco antes dela deixar Roma, o prefeito da cidade fora massacrado pelo povo sublevado contra ele num distúrbio provocado pela falta de pão (VITA MEL., 19).
Portanto, o medo da violência e do poder do povo enfurecido era bastante fundado. $\mathrm{O}$ argumento de Agostinho de que não houvera perigo real quando o juramento foi feito é pouco convincente. Ele, no entanto, procura em sua carta minimizar o perigo que Piniano correra: "o persistente clamor do povo e apenas isto" o forçara ao juramento. Fala da composição da multidão: " alguns homens atrevidos, misturados com a multidão formada por homens de bem, poderiam pelo desejo de pilhagem irromper em atos criminosos de violência, caso encontrassem pretexto para desordens e para justa indignação". Procurando demonstrar a obrigação de Piniano honrar sua promessa ao povo de Hipona, afirma que quando o juramento foi feito não havia certeza de que o medo da violência se transformasse em agressão mais concreta ${ }^{6}$.

Já na carta endereçada a Albina ele inicia: "nada foi feito pelo povo de Hipona contra nosso santo irmão, seu genro Piniano, que pudesse despertar nele o medo da morte, embora ele tenha sido acometido por este temor". Em seguida expressa sua preocupação com "os malvados que com freqüência se juntam numa multidão em secreta conspiração", podendo "irromper em atrevimento violento, se encontrassem ocasião para iniciar uma revolta" ". Segundo Agostinho nada disto ocorrera; apenas o bispo Alípio foi agredido verbalmente: "o povo fez clamorosamente expobrações muito indignas contra ele". Repele a acusação de que o povo agiu motivado por razões indig-

\footnotetext{
${ }^{6}$ Nunc vero cum tantummodo populi perseverantissimus clamor, ad nullum nefas hominem cogeret, sed ad id quod si fieret, licite fieret; cunque metueretur quidem ne aliqui perditi, qui multitudini etiam bonorum plerumque miscentur, occasione seditionis et quasi justae indignationis inventa, in aliquam vim sceleratam rapinarum cupiditate prorumperent, sed tamen illud quod metuebatur esset incertum (EPIST. CXXV, 3).

${ }^{7}$ Nam et nos metuebamus ne ab aliquibus perditis, qui saepe multitudini occulta conspiratione miscentur, in violentam prorumperetur audaciam, occasione seditionis inventa... (EPIST. CXXVI, 1).
} 
nas, mas reconhece que na multidão podiam estar misturados alguns indigentes ou mendigos que ajudaram a aumentar o clamor popular, agindo com esperança de algum auxílio para suas necessidades vindo da respeitável riqueza de Piniano; na opinião dele, isto não pode ser considerado como vergonhosa cobiça ${ }^{8}$.

Descreve a negociação que se seguiu até terminar pelo acordo de que Piniano não seria ordenado, mas fixaria residência em Hipona. Fica evidente que a pressão da massa reunida na igreja era considerável: "a multidão reunida defronte a escadaria persistia na mesma determinação, com terrível clamor e gritos"; "todo o tempo foram feitas recriminações indignas contra meu irmão Alípio; neste momento temíamos consequências mais sérias”.

Agostinho acaba admitindo a ameaça que sofreu ao enfrentar a multidão. Afirma que permaneceu fiel a sua promessa "mesmo face a tal perigo. Verdade é que mais tarde se verificou ser sem fundamento tal receio, mas o medo era compartilhado por todos nós igualmente". Temia que o povo se tornasse exasperado pelo desapontamento e menos contido pelo sentimento de reverência. Temia sobretudo por Alípio; não podia se retirar da igreja, "deixando-o sob o poder do povo enfurecido (furenti populo)" (EPIST. CXXVI, 2).

Agostinho funcionou como mediador na negociação, conseguindo que a multidão fizesse silêncio para ouvir a proposta de Piniano. Quando esta foi aceita, foi formalizado um documento assinado por Piniano e outros bispos presentes.

No século V, ao lado das tradicionais relações entre os magistrados e a plebe urbana, encontramos desenvolvidas novas relações referentes a "ricos" e "pobres" dentro da conduta cristã de distribuição de

\footnotetext{
${ }^{8}$ Nam etsi fuerint illi multitudini permixti inopes vel mendici, qui simul clamabant, et de vestra venerabili redundantia indigentiae suae supplementum sperabant; nec ista, ut arbitror, cupiditas turpis est (EPIST. CXXVI, 7).
}

esmolas e doações às comunidades. O comportamento, tanto dos aristocratas -incluindo-se aqui Agostinho, com sua mentalidade permeada de valores da cultura romana, embora cristão-, quanto do populus, é calcado numa relação quase contratual pré-existente. Culturalmente já existia uma expectativa de direito da plebe receber da nobreza o atendimento às suas reivindicações. Agostinho usa termos técnicos ao discutir se Piniano está obrigado ou não a cumprir a promessa que lhe foi extorquida, recorrendo mesmo a exemplos da época da República romana. Piniano não será culpado de perjúrio, nem será assim considerado pelos habitantes de Hipona, a não ser que não corresponda à expectativa deles ${ }^{9}$. É perjuro quem ilude a expectativa daqueles para quem jurou (EPIST. CXXV, 4).

Persiste o comportamento contraditório dos aristocratas romanos: um sentimento de responsabilidade para com a plebe urbana, misturado com um certo desprezo aliado a um temor latente pela violência que podia irromper na multidão incontrolada.

O vocabulário empregado reflete esta atitude, remetendo a alguns termos tradicionais das instituições romanas: a "plebs" de Tagaste, o "populus" de Hipona. A conotação pejorativa aparece claramente em outros: "relicta turba", "multitudo", "perditi", e nos qualificativos "imperitum vulgus", "furenti populo", "populus tumultuante"; o episódio é considerado relacionado com "conspirationes" e "seditiones". Conceitos novos aparecem dentro do novo espaço cristão, com referências a "populo christiano", "honestos fideles", menção à pobreza cristã (christiana paupertas), à "indigentia" e preocupação com os fracos/vulneráveis (infirmus).

Ao longo do tempo, a convivência dentro do mesmo espaço urbano desenvolvera padrões culturais de comportamento, existindo por parte da plebe uma ex-

\footnotetext{
${ }^{9}$ Ac per hoc perjurus nec erit, nec ab eis putabitur, nisi eorum exspectationem deceperit.
} 
pectativa de receber da nobreza o atendimento às sua reivindicações. No período romano tardio, estas relações, que colocavam face a face grupos sociais tão

\section{Bibliografia}

AMMIANO MARCELLINO. Istorie. Testo latino, traduzione e note di A. Resta Barrile. Bologna, Zanichelli, 1981.

AURELIUS AUGUSTINUS. Opera omnia, em Patrologia Latina. Paris, J.-P. Migne, 1865, t.33, Epist. CXXV-CXXVI, col. 473-483.

BROWN, P. "Dalla "Plebs Romana" alla "Plebs Dei”: aspetti della cristianizzazione di Roma". Governanti e intellettuali. Popolo di Roma e popolo di Dio (I-VI secolo). Torino, Giappichelli Editore, 1982, p.93-121.

GIARDINA, A. "Carità eversiva: le donazioni di Melania la diversos, tornam-se ainda mais complexas pela contribuição cristã, com o "povo de Deus" utilizando o secular aprendizado anterior enquanto plebe romana.

Giovane e gli equilibri della società tardoromana". Studi Storici, n. 1, 1988, p.127-142.

GOYAU, G. Sainte Mélanie. 12 ed. Paris, Victor Lecoffre, 1925.

STE. CROIX, G.E.M. De. "Suffragium: from vote to patronage". British Journal of Sociology. mar. 1954. v.5, n.1, p. 33-48.

THOMPSON, Edward P. Società patrizia, cultura plebea. Torino, Giulio Einaudi, 1982.

VIE de Sainte Mélanie. Texte grec, introduction, traduction et notes par Denys Gorce. Paris, Les Éditions du Cerf, 1962, (Sources Chrétiennes, 90). 